\title{
Photogrammetric Analysis of CPAS Main Parachutes
}

\author{
Eric S. Ray ${ }^{1}$ \\ Jacobs ESCG, Houston, TX, 77598 \\ David Bretz $z^{2}$ \\ Barrios Technology ESCG, Houston, TX, 77598
}

\begin{abstract}
The Crew Exploration Vehicle Parachute Assembly System (CPAS) is being designed to land the Orion Crew Module (CM) at a safe rate of descent at splashdown with a cluster of two to three Main parachutes. The instantaneous rate of descent varies based on parachute fly-out angles and geometric inlet area. Parachutes in a cluster oscillate between significant fly-out angles and colliding into each other. The former presents a sub-optimal inlet area and the latter lowers the effective drag area as the parachutes interfere with each other. The fly-out angles are also important in meeting a twist torque requirement. Understanding cluster behavior necessitates measuring the Mains with photogrammetric analysis. Imagery from upward looking cameras is analyzed to determine parachute geometry. Fly-out angles are measured from each parachute vent to an axis determined from geometry. Determining the scale of the objects requires knowledge of camera and lens calibration as well as features of known size. Several points along the skirt are tracked to compute an effective circumference, diameter, and inlet area as a function of time. The effects of this geometry are clearly seen in the system drag coefficient time history. Photogrammetric analysis is key in evaluating the effects of design features such as an Over-Inflation Control Line (OICL), Main Line Length Ratio (MLLR), and geometric porosity, which are varied in an attempt to minimize cluster oscillations. The effects of these designs are evaluated through statistical analysis.
\end{abstract}

\section{Nomenclature}

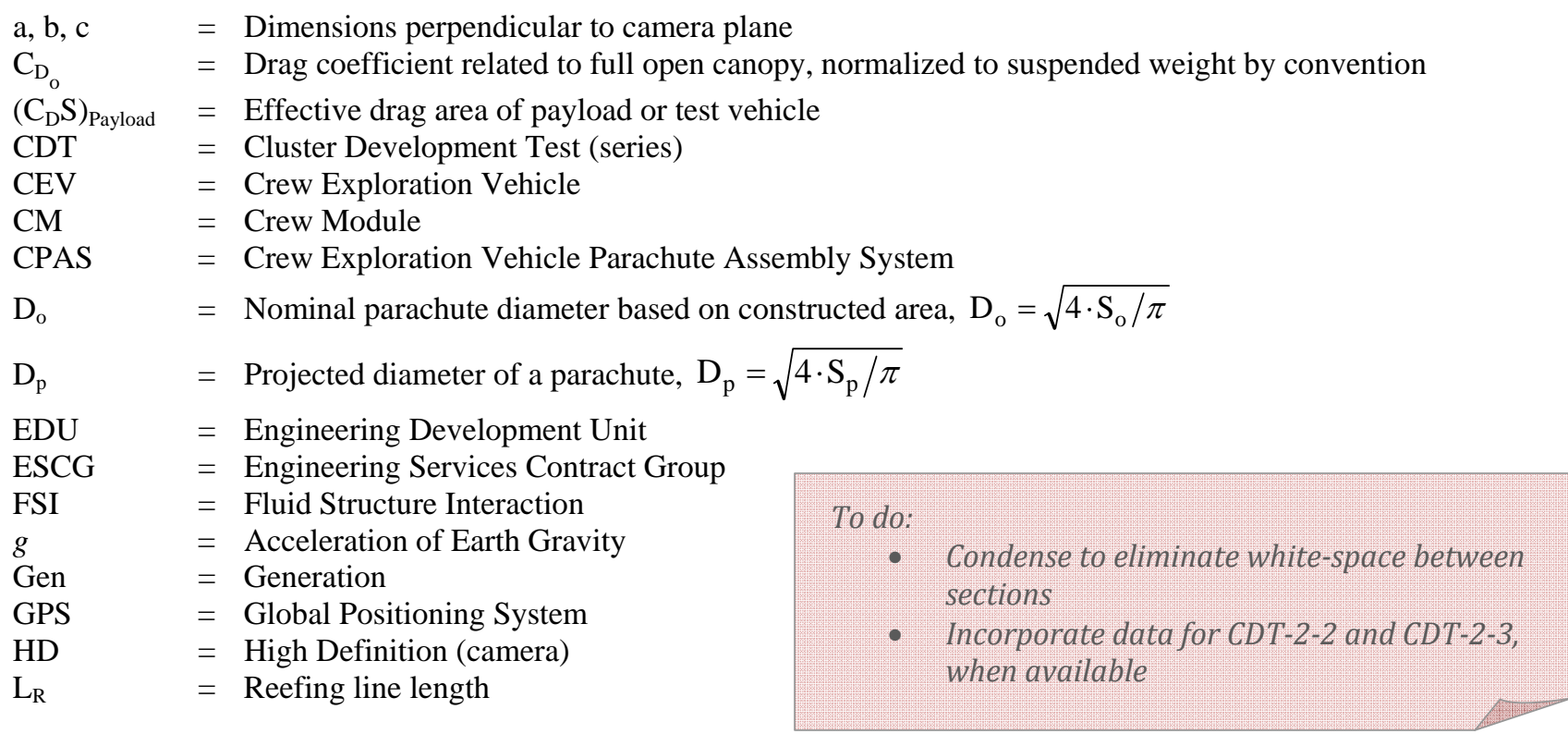

${ }^{1}$ Analysis Engineer, Aerothermal and Flight Mechanics, 455 E. Medical Center Blvd., Webster, TX, AIAA Member.

${ }^{2}$ Image Science \& Analysis Group, JSC-KX. 


\begin{tabular}{|c|c|c|}
\hline $\mathrm{L}_{\mathrm{s}}$ & $=$ & Suspension line length \\
\hline MDT & $=$ & Main Development Test (series) \\
\hline MLLR & $=$ & Main Line Length Ratio \\
\hline MSL & $=$ & Mean Sea Level \\
\hline $\mathrm{N}_{\mathrm{c}}$ & $=$ & Number of parachutes in a cluster \\
\hline OICL & $=$ & Over-Inflation Control Line \\
\hline PSF & $=$ & Parachute Shape Factor \\
\hline $\bar{q}$, qbar & $=$ & Dynamic pressure, $\overline{\mathrm{q}}=\frac{1}{2} \cdot \rho \cdot \mathrm{V}_{\text {air }}{ }^{2}$ \\
\hline $\mathrm{r}$ & $=$ & Measured radius of parachute at skirt plane \\
\hline$r_{\text {Ring }}$ & $=$ & Radius of parachute at plane of reference ring \\
\hline$\rho$, rho & $=$ & Humidity-Corrected Atmospheric Density \\
\hline$\rho_{\mathrm{SL}}$ & $=$ & Sea level density constant \\
\hline SD & $=$ & Standard Definition (camera) \\
\hline$\sigma$, sigma & $=$ & Standard deviation (general) \\
\hline $\mathrm{S} / \mathrm{N}$ & $=$ & Serial Number \\
\hline $\mathrm{S}_{\mathrm{o}}$ & $=$ & Parachute Canopy open reference area based on constructed shape \\
\hline $\mathrm{S}_{\mathrm{p}}$ & $=$ & Projected frontal canopy area \\
\hline $\mathrm{S}_{\mathrm{P}_{\mathrm{c}}}$ & $=$ & Projected frontal canopy area of a cluster \\
\hline$S_{\text {Ring }}$ & $=$ & Scale between physical length and pixels at plane of chosen Ring \\
\hline$S_{\text {skirt }}$ & $=$ & Scale between physical length and pixels at plane of parachute skirt \\
\hline$\theta_{\mathrm{i}}$, theta & $=$ & Fly-out angle for parachute i \\
\hline TMS & $=$ & Tension Measurement System \\
\hline TSE & $=$ & Test Support Equipment \\
\hline UTC & $=$ & Coordinated Universal Time \\
\hline $\mathrm{V}_{\text {air }}$ & $=$ & Total airspeed relative to air mass \\
\hline $\mathrm{V}_{\mathrm{Z}}$ & $=$ & Downward vertical velocity or rate of descent \\
\hline $\mathrm{V}_{\mathrm{Z}_{\mathrm{SL}}}$ & $=$ & Sea level equivalent rate of descent \\
\hline $\mathrm{W}_{\text {Payload }}$ & $=$ & Suspended weight of payload \\
\hline YPG & $=$ & Yuma Proving Ground \\
\hline
\end{tabular}

\section{Introduction}

$\mathrm{T}$ HE Crew Exploration Vehicle Parachute Assembly System (CPAS) is required to safely land the Orion Crew Module (CM) at a rate of descent not to exceed 33 feet per second at sea level on a standard day. Flight tests are being conducted to test and refine the design against this requirement. The steady-state drag coefficient and rate of descent vary considerably during the Main parachute phase due to parachute "breathing," cluster interaction, and atmospheric anomalies such as updrafts and wind gusts. Therefore, understanding parachute performance involves a combination of improved modeling fidelity of these individual factors and a large base of tests from which to draw statistics.

Another CPAS requirement has to do with the torque induced by the twisting of Main parachute risers. The Orion guidance system is being designed to orient the capsule to a favorable roll attitude at splashdown. This will be accomplished by using reaction control thrusters to overcome torque induced by Main parachute riser twist. Two CPAS ground tests have shown that twist torque is a function of riser fly-out angles as well as the total twist angle. Therefore, understanding the parachute cluster geometry in flight is necessary to simulate and predict twist torque.

Insight into cluster dynamics has been improved through photogrammetric analysis. Generally, an upwardlooking camera is mounted on the test vehicle to track the Main parachutes. This technique has been successful for other programs and types of parachutes. ${ }^{1}$ Features can be tracked through every video frame to estimate instantaneous system geometry. Parachute tests often include optical tracking of the payload position and attitude from multiple ground cameras. ${ }^{2}$ Calculating the 3-D position of features on a parachute from cameras mounted on the payload is hindered by the relatively short possible baseline between cameras. Therefore, the analysis to date for CPAS has relied on a single camera image at a time and a priori knowledge of the geometry. 


\section{Data Reduction Method}

The performance of the CPAS Main parachutes is determined by measurements based on velocity, which are known to vary with time in a complicated fashion. Photogrammetry provides a complementary method of understanding the temporal changes of the parachute cluster by breaking down the system into measureable components. The time-varying nature of these components may be easier to characterize, eventually leading to a better prediction of the entire system.

Photogrammetric analysis accounts for the radial lens distortion of every camera (or an identical model, if the original is not available) by generating a map using the camera image on a grid of known dimensions. All feature tracking was performed using the TrackEye motion analysis software from Photo-Sonics, Inc. ${ }^{3}$

\section{A. Steady-State Parachute Performance}

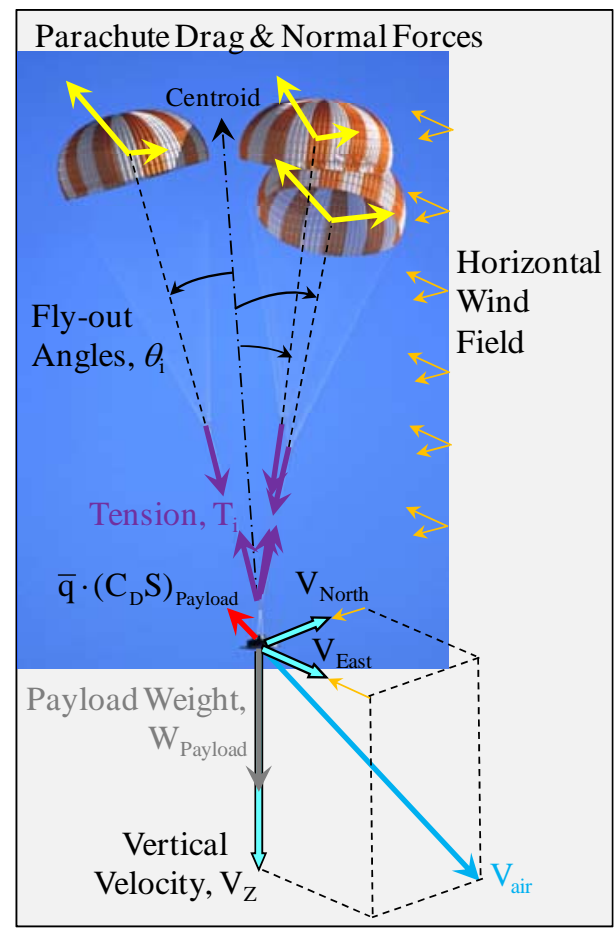

Figure 1. Parachute cluster diagram.
A single parachute is considered to be in steady-state descent when the drag force is equal to the payload weight. The force balance for a cluster is more complex, as illustrated in Fig. 1. Steady-state can be determined when the test vehicle has first decelerated to $1 \mathrm{~g}$.

Horizontal components of airspeed are computed by subtracting the horizontal wind components from the inertial velocity; instantaneous updrafts and downdrafts are currently not measured due to their transient nature. The inertial vertical velocity and windcorrected horizontal velocity are used to compute local airspeed, $\mathrm{V}_{\text {air }}$. Tension in each riser, $\mathrm{T}_{\mathrm{i}}$, can be decomposed by measuring parachute fly-out angles, $\theta_{\mathrm{i}}$. This allows for comparison with loads from an accelerometer.

Simplifications are used to compute the cluster steady-state drag coefficient in Eq. (1). The total parachute area is the number of parachutes in the cluster, $\mathrm{N}_{\mathrm{c}}$, multiplied by the reference area, $\mathrm{S}_{0}$. By CPAS convention, the full open steady-state drag coefficient, $C_{D_{o}}$, is normalized to the suspended weight of the payload, $\mathrm{W}_{\text {Payload, }}$ which does not include the weight of the parachute material and suspension equipment. The parachute steady-state drag coefficient is defined using purely vertical velocity, $\mathrm{V}_{\mathrm{Z}}$, which neglects any parachute gliding motion. To isolate parachute drag, the drag area of the payload or vehicle, $\left(C_{D} S\right)_{\text {Payload, }}$ must be subtracted from the system drag area. The ambient air density, $\rho$, is used to normalize test data. A thorough description of the measurement instrumentation and techniques for these quantities can be found in Ref. 4 .

$$
\mathrm{C}_{\mathrm{D}_{\mathrm{o}}}=\frac{1}{\mathrm{~N}_{\mathrm{c}} \cdot \mathrm{S}_{\mathrm{o}}} \cdot\left(\frac{\mathrm{W}_{\text {Payload }}}{\frac{1}{2} \cdot \rho \cdot \mathrm{V}_{\mathrm{Z}}^{2}}-\left(\mathrm{C}_{\mathrm{D}} \mathrm{S}\right)_{\text {Payload }}\right)
$$

Parachute rate of descent performance at altitude with varying atmospheric conditions are normalized to the sea level equivalent rate of descent, $\mathrm{V}_{\mathrm{Z}_{\mathrm{SL}}}$, for a standard day at standard sea level density, $\rho_{\mathrm{SL}}$, as defined in Eq. (2). Once transient inflation effects have damped, data from the entire steady-state descent are checked against the requirement.

$$
\mathrm{V}_{\mathrm{Z}_{\mathrm{SL}}}=\mathrm{V}_{\mathrm{Z}} \cdot \sqrt{\frac{\rho}{\rho_{\mathrm{SL}}}}
$$




\section{B. Fly-Out Angle Computation}

The axis which defines the fly-out angles varies as the system oscillates in a pendulum-like motion, as illustrated in Fig. 2. Each upward-looking camera is fixed to the platform, but is always offset from the center of the platform. The center axis must be determined on each 2-D video image through observations of the parachute center vents.

The fly-out angles are calculated entirely in image space coordinates from data gathered from distortion-corrected imagery and using perspective geometry. In Fig. 3, the pixel coordinates of the parachute vents $(\mathrm{A}, \mathrm{B})$ and the fly-out center $(\mathrm{C})$ define vectors emanating from the perspective center (PC). The perspective center lies one focal length (f) away from the principal point (PP), in a direction perpendicular to the image. In this example, the principal point is drawn exactly at the center of the image, though in the actual cameras, it was located some distance away from it. The fly-out angles are simply the angles between the image space vectors (a) and (b) and the fly-out center vector (c).

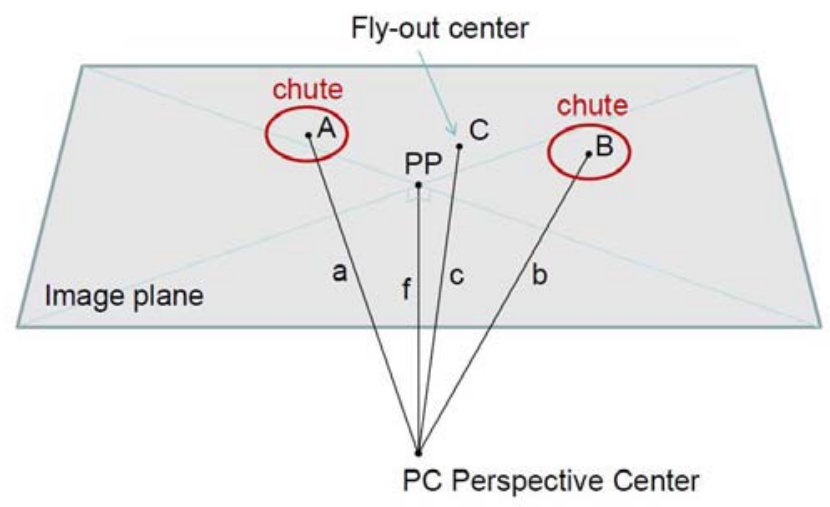

For a three parachute system, the center axis is estimated to lie at the geometric centroid of the cluster vents. The centroid point was calculated for every frame and is dynamic. For a two-parachute system, the axis was determined by superimposing images at several instances, drawing lines connecting the vents and finding the intersection of those lines. The intersection point for two parachutes is determined only once, so it is static. A sample multi-exposure is shown in Fig. 4. Note that the axis is not at the image center because the camera is not directly below the confluence fitting and is not pointed precisely in the axis direction.

Figure 3. Fly-out angle vectors in image space.

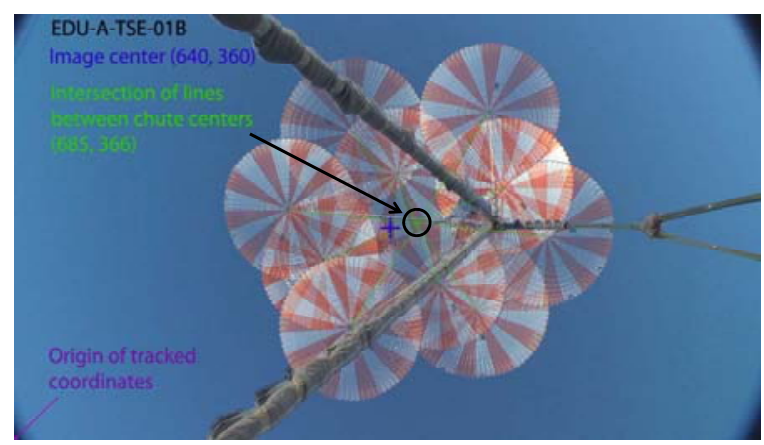

Figure 4. Fly-out angle axis for a two-parachute test. 


\section{Parachute Shape Tracking}

CPAS Main parachutes have a noticeable cyclical expansion and contraction called "breathing" which can measurably affect performance. In addition, parachutes in a cluster distort their shapes when they collide, or even when they are close enough for their "spillover" flow to interfere with each other. The reduction in canopy projected area, $S_{\mathrm{p}}$, leads to a loss in drag and an increase in descent rate. To quantify this effect, several points along the skirt are tracked at the interface between orange and white colors every fourth gore, as shown in Fig. 5. There is often some ambiguity in the skirt edge where the skirt "rolls up." The total projected area for each parachute can be computed by adding the twenty

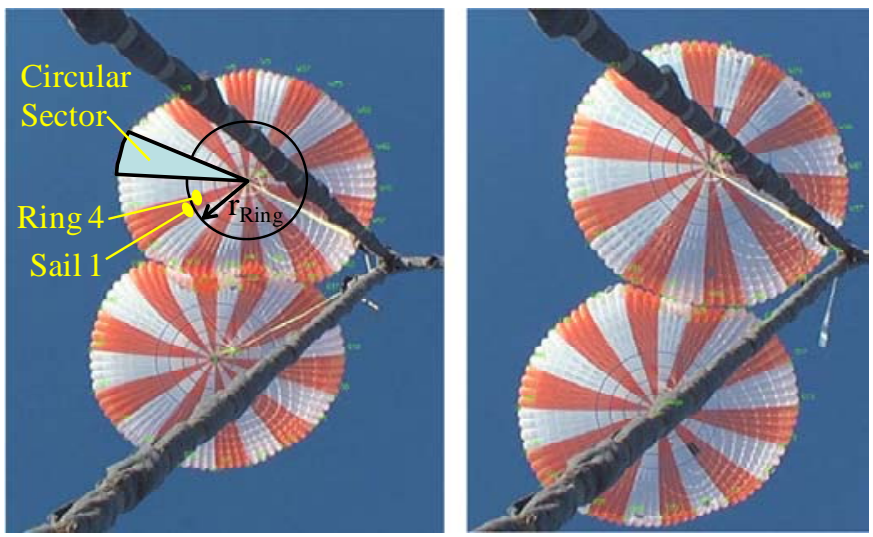

Figure 5. Skirt point tracking during a typical collision. wedge-shaped pieces swept out between adjacent skirt points either as triangles or, more accurately, as the sum of circular sectors.

Unlike the fly-out angle analysis, tracking the physical dimensions of the parachutes requires mapping pixel coordinates to actual lengths at various distances from the camera. CPAS Main parachute geometry is shown in Fig. 6 . In a given frame, the distance from the camera to the Main parachute skirt can be estimated with the known lengths of the suspension lines, $\left(L_{s}\right)$, riser $\left(L_{R}\right)$, and harness legs, and a feature on the canopy such as the radius of a ring $\left(\mathrm{r}_{\text {Ring }}\right)$. However, as the parachute radius (r) increases during "breathing," the vertical distance between the ring plane and skirt plane (a) and the vertical length of the suspension lines (b) will decrease. It is assumed that the lines do not stretch appreciably.

The distortion of the canopy in a given frame is described by the Parachute Shape Factor (PSF), defined in Eq. 3. An initial guess of the inflated Main parachute cross-sectional
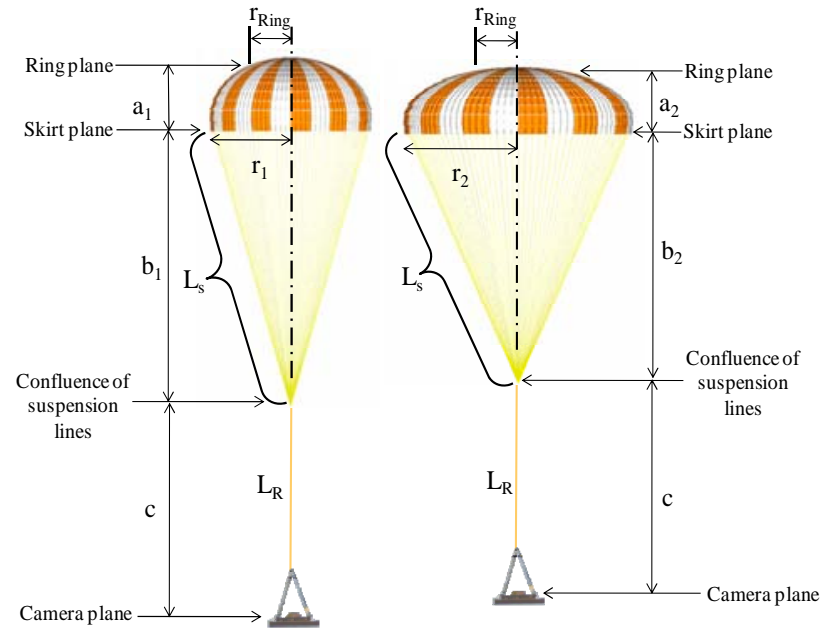

Figure 6. Variation in Main parachute geometry. shape were provided from Fluid Structure Interaction (FSI) simulations from Rice University. ${ }^{5}$

$$
\operatorname{PSF}=(b+c) /(a+b+c)
$$

Three methods of various levels of complexity were evaluated by the KX group to determine the physical dimensions of the canopy. All used the known dimension of 18.856 feet for the largest of the 4 concentric rings (the gap between Ring 4 and Sail 1) on the Main parachute for scale.

- Constant Scale: For each frame, use Ring 4 to get the scale at the ring plane $\left(S_{\text {Ring }}\right)$. Assume the parachutes hold a constant shape to get the scale at the skirt plane $\left(S_{\text {skirt }}\right)$ for each frame. Use the median $S_{\text {skirt }}$ value for each parachute excluding parachute collisions (i.e. when distance between centers is less than 83 feet). The problem with this method is that the distance to the skirt plane gets closer as the diameter increases. This method overestimates the maximum diameter.

- Variable Scale, Constant Parachute Shape: Same as Constant Scale factor, but instead of using a median $S_{\text {skirt }}$ value for all frames, use the value derived for each frame (and each parachute). The problem with this method is that the parachute is changing shape, so the Ring 4 plane and the skirt plane are not always at the same distances. As diameter increases, the ring plane gets closer. This method underestimates the skirt diameter.

- Variable Scale, Variable Parachute Shape: Same as the Variable Scale, but once an initial skirt diameter is computed, use that to estimate a parachute shape and calculate a variable Parachute Shape Factor for each frame and use that to get the scale at the skirt plane. 
The last method was chosen as the most accurate and is shown in the flowchart in Fig. 7. Although the method can be used iteratively, a single pass was determined to produce an acceptable level of accuracy.

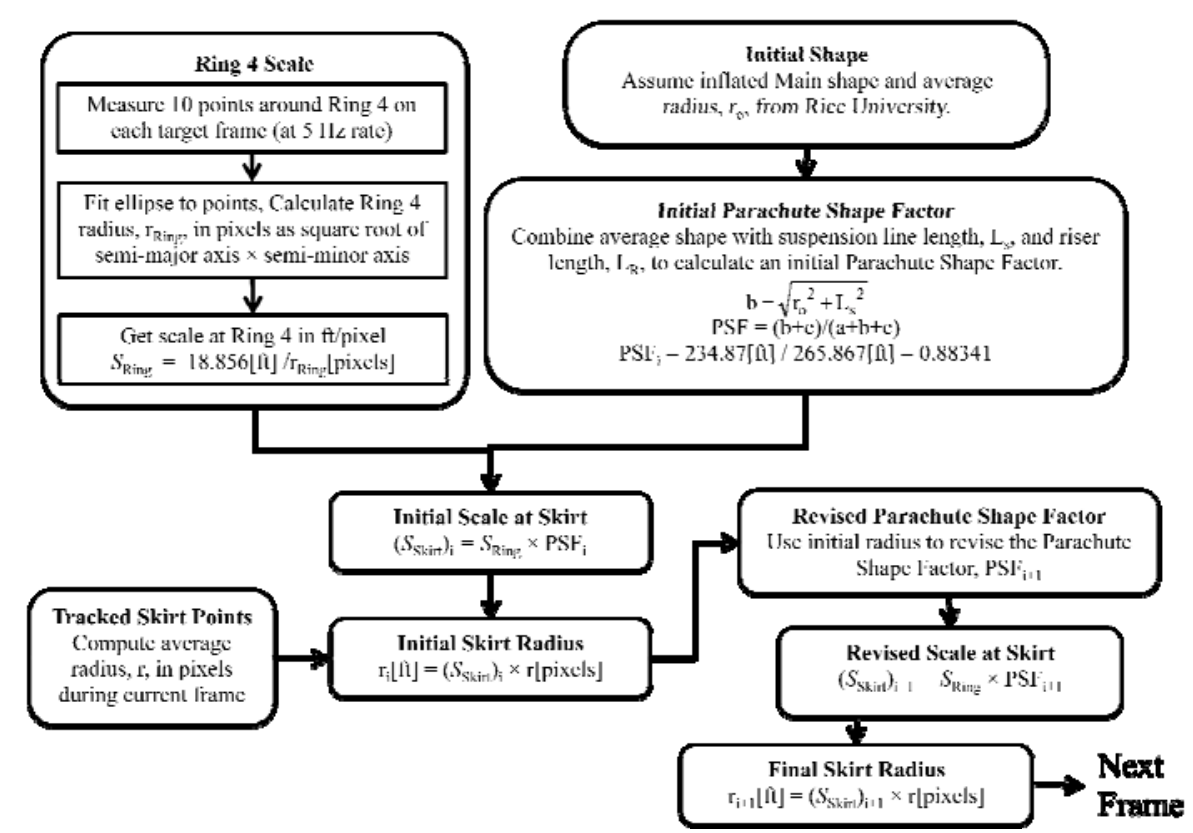

Figure 7. Variable Scale, Variable Parachute Shape flow chart.

\section{Cluster Projected Area}

The total geometric projected area of the cluster, $\mathrm{S}_{\mathrm{p}_{\mathrm{c}^{\prime}}}$, can be computed from the fly-out angles and parachute shapes. Large fly-out angles will move the parachute inlet out of the flow, reducing efficiency. This effect is less severe than the loss of inlet area during parachute collisions. Assuming each parachute skirt makes a plane perpendicular to the parachute axis, the contribution from each parachute is the projected area scaled by the dot product of the parachute axis vector with the relative airspeed vector.

Computing each parachute orientation relative to the airflow is difficult and prone to uncertainty because it involves combining several measurements from different sources and in different reference frames: the wind field, the system inertial velocity, the platform orientation, and the parachute orientation relative to the platform. Such analysis will be considered in the future to quantify individual parachute lift and drag coefficients as a function of total angle of attack.

However, for the current analysis, some simplifications have been made. It is assumed that the deceleration vector is coincident with the fly-out center

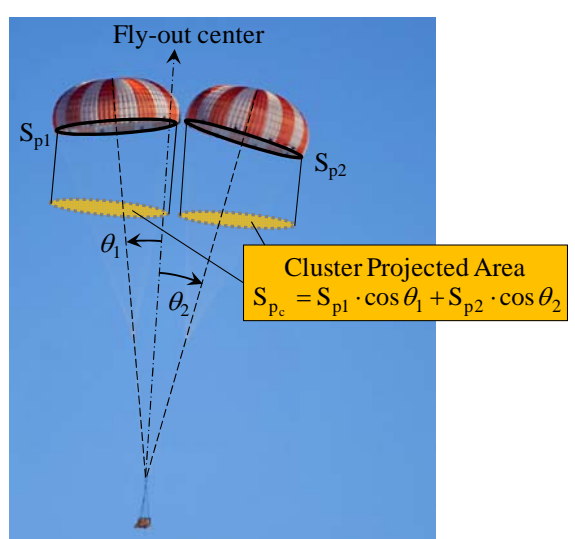

Figure 8. Simplified cluster projected area.

axis, as shown in Fig. 8. The cluster projected area equation for a two-parachute cluster is shown in the figure. A more generic form is Eq. 4.

$$
\mathrm{S}_{\mathrm{p}_{\mathrm{c}}}=\sum_{\mathrm{i}=1}^{\mathrm{i}=\mathrm{N}_{\mathrm{c}}}\left(\left(\mathrm{S}_{\mathrm{p}}\right)_{\mathrm{i}} \cdot \cos \theta_{\mathrm{i}}\right)
$$




\section{Selected Flight Test Results}

Photogrammetric analysis has been performed on single-Main and cluster-of-Mains CPAS flight tests. While the single Main tests display some "breathing," the cluster effects are the most significant component of steady-state rate of descent performance. Only tests with clusters of two or three Mains will be presented, because these are representative of the Orion landing configuration.

\section{A. CDT-1}

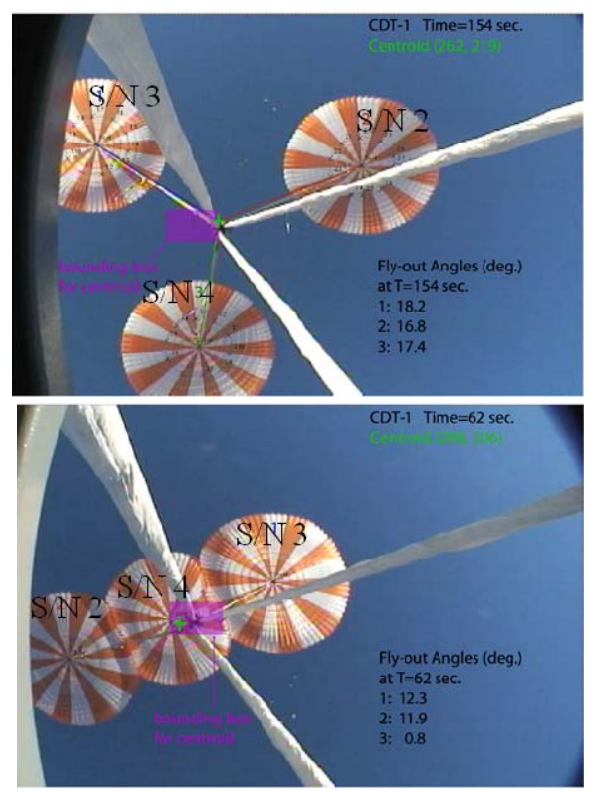

Figure 9. CDT-1 fly-out angles.

Because the fly-out angles were measured with respect to the cluster centroid position (a dynamic point measured on each frame), the small shifts in camera direction were cancelled out and did not affect the fly-out calculations. The time histories of each Main parachute flyout angle are plotted in Fig. 10a. The fly-out angle for Main $\mathrm{S} / \mathrm{N} 4$ is nearly zero from about 63 to 70 seconds when all three parachutes form a straight line. The skirt perimeters (Fig. 10b) were calculated by tracking 20 points for each parachute. Fig. 10c plots the projected diameters for each parachute, $D_{p}$. These are the diameters of circles with the equivalent area of the computed projected areas, and are thus proxies for $S_{p}$. The period of the parachute "breathing," indicated by the perimeter and diameter, is about 4 to 6 seconds, while the fly-out period is on the order of 20 seconds.

Each plot also includes bars indicating parachute collisions. The bars only rise to the level of the corresponding data for the two or three Main parachutes involved in the collision. For example, the collisions at 95 seconds and 165 seconds involved Mains S/N 2 and S/N3, but S/N 4 was further away and did not collide.
The first CPAS Cluster Development Test, CDT-1, was conducted on October 18, 2007. The test vehicle was a parachute compartment mockup mounted on a 9×20 ft Type V platform. Three CPAS $116 \mathrm{ft}$ Gen I Main parachutes were used for the steady-state descent, which began at about 3,790 ft above Mean Sea Level (MSL) and lasted for about 110 seconds. The suspended weight of the payload was set to approximate the Orion design at the time of $16,462 \mathrm{lbm}$.

Images from an upward-looking Standard Definition (SD) camera (720 $\times 420$ pixels) are shown in Fig. 9. On CDT-1, the upward looking camera used for analysis was not firmly mounted. It became slightly loose on its mount, allowing some variation in the pointing direction. The extent of the variation in cluster centroid is shown by the purple bounding box. The Mains were not marked, so identification was accomplished by following each parachute's deployment from known bays frame-by-frame.

(a)

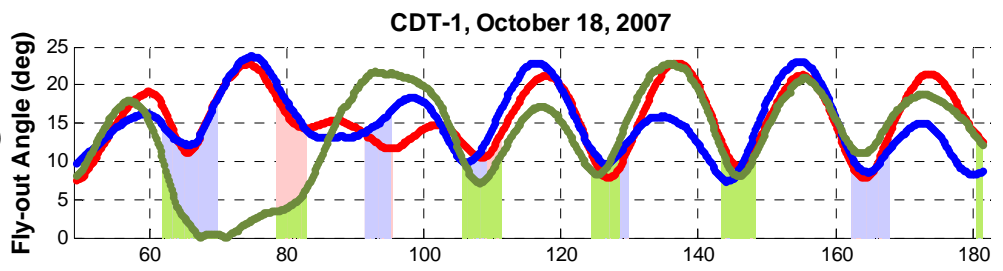

(b)

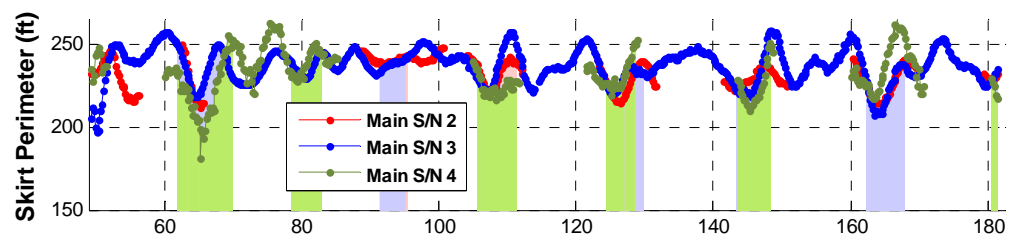

(c)

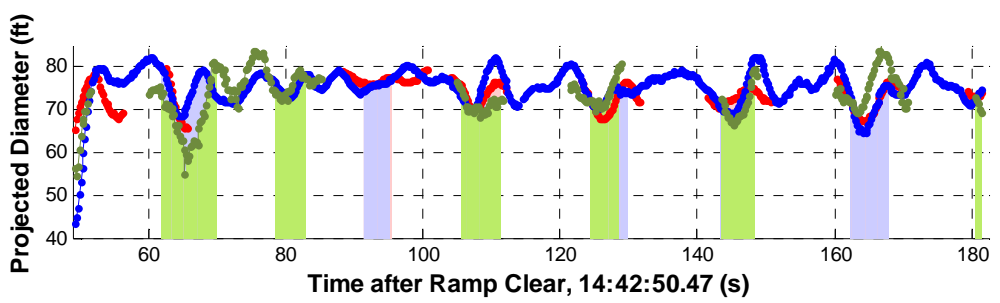

Figure 10. CDT-1 steady-state (a) Fly-out angles, (b) Skirt perimeters, and (c) Projected inlet diameters for each Main parachute. 
Notice that much of the data are missing from the time histories. Only the vent needs to be visible to compute the fly-out angle of a parachute in a given frame. However, when a large part of any parachute is out of the field of view, not enough points along the skirt are available to compute the perimeter or $D_{p}$ at that instant.

A statistical analysis of fly-out angles was performed on all available tests to not only compute the maximum encountered angle, but to predict the maximum reasonable expected possible fly-out angle. Histograms of the fly-out angles for each parachute are shown in Fig. 11. A Gaussian curve is fit to each histogram, with mixed results. Each histogram appears bi-modal because the portion of the flight where Main S/N 4 is "trapped" between the other two is distinct from the rest of the flight. The mean and $99.74 \%$ ( $3 \sigma$ equivalent) minimum and maximum fly-out angles are shown. Because S/N 4 had a small fly-out angle, the lower tail is less than zero, which is physically impossible. However, if the data are combined together, a Gaussian fit is much more appropriate, as shown in the lower right. The concatenated data are fit to a Gaussian curve with a mean of 14.61 deg. and a standard deviation of 4.88 deg. The extremely low angles from Main S/N 4 are still visible, but are diluted with the rest of the data. Assuming a three Main cluster of a similar canopy would act in the same manner as this test, the $3 \sigma$ equivalent maximum fly-out angle is 29.25 degrees, which is higher than the highest experienced angle of 23.8 degrees.

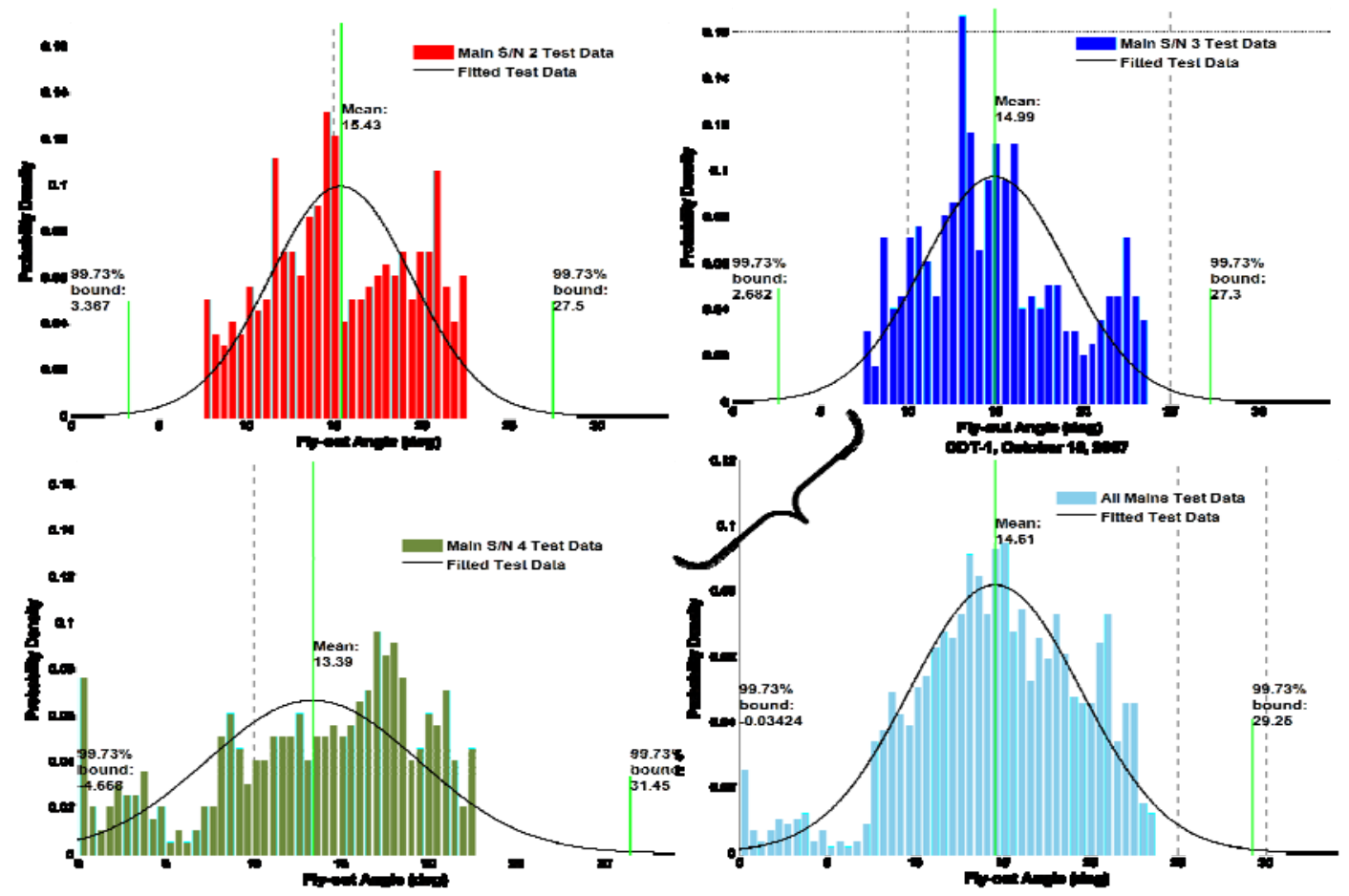

Figure11. CDT-1 fly-out angle histograms. The lower right histogram uses the combined data from all three Main parachutes

The parachute fly-out angles were useful in determining riser loads. Each riser was instrumented with a Tension Measuring System (TMS). However, it was later discovered that the calibration was inappropriate for the type of material used. By resolving the TMS readings into components based on the fly-out angles, it was possible to recalibrate the TMS data based on the loads calculated from accelerometers. It was known that the total resultant load was the sum of each measured riser tension times the cosine of the fly-out angle, as in Eq. (5). A best-fit measurement gain was determined by setting the corrected angle equal to the loads from the accelerometer. This resulted in more accurate riser loads appropriate for load sharing analysis.

$$
\mathrm{T}_{\text {flyout }}=\sum_{\mathrm{i}=1}^{\mathrm{i}=\mathrm{N}_{\mathrm{c}}}\left(\mathrm{T}_{\mathrm{i}} \cdot \cos \theta_{\mathrm{i}}\right)
$$


The load measurements were then used to compute the drag area by dividing the resultant load by the instantaneous dynamic pressure. Using the sum of the tension measurements without accounting for the flyout angles will result in a drag area curve that is too high. The drag area corrected for fly-out angles compares more favorably than without fly-out correction to the drag area from accelerometers, as shown in Fig. 12.

The individual components of the cluster projected area are plotted in Fig. 13. The total cluster projected area, plotted in black, is only available when all three parachutes are in the field of view simultaneously. This only occurred for a few seconds at a time during the "crashing" events, indicated by the vertical bars. The drag coefficient is plotted in light blue on the secondary axis to demonstrate the correlation between loss of projected area and loss of instantaneous drag.

There appears to be a slight lag between when each crash is visible and the corresponding drop in drag coefficient. This may be due to the slow system response because the Main parachute canopies are about two hundred feet behind the payload. In addition, the video data may not be properly synchronized because no timecode was available and the touchdown event was not recorded.

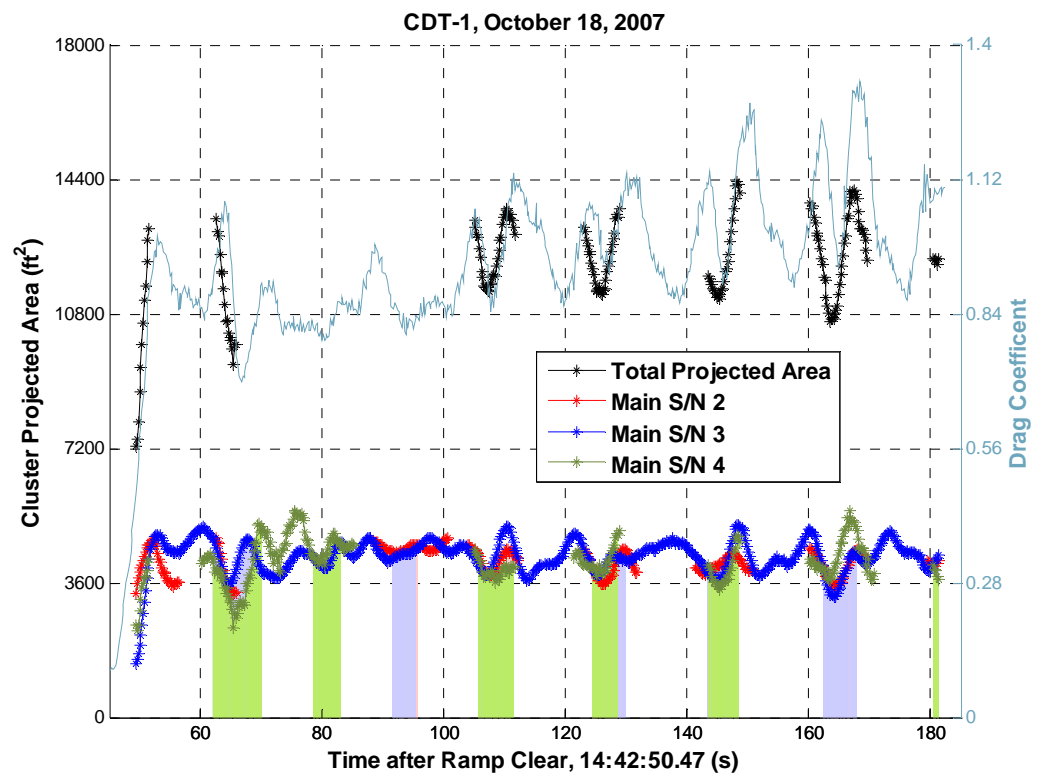

Figure 13. CDT-1 cluster projected area and drag coefficient. 
B. CDT-3

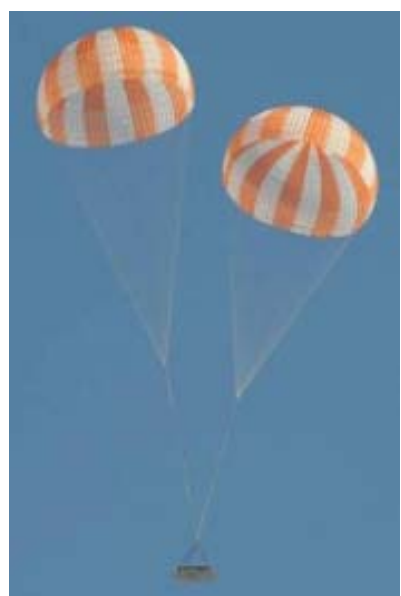

Figure 14. CDT-3 Main parachutes.

CDT-3 was conducted on June 17 , 2008, and employed a cluster of two CPAS Mains (Fig. 14). CPAS must meet the landing rate of descent requirement with as few as two Mains. CDT-3 was the first test conducted with this limiting case. The test vehicle was a weight tub mounted on a $9 \times 20 \mathrm{ft}$ Type $\mathrm{V}$ platform at a similar suspended weight to CDT-1.

There were several lessons learned from video problems on this test that were applied to the second generation (Gen II) tests. Most importantly, the fields of view of the onboard SD cameras were too narrow, as shown in Fig. 15. Because the vents were only visible on both Mains simultaneously for a small fraction of the time, a useful fly-out analysis could not be conducted. Further tests used pre-visualization software with geometric models to choose the optimal camera locations, lenses, and settings to ensure obtaining relevant imagery.

The upward-looking camera for this test used an integrated tape recorder. Jarring the camera caused skipped or repeated frames, preventing time synchronization with other data sources. Later testing used High Definition (HD) cameras with solid-state recorders, which generally did not have this problem. Efforts were also made in Gen II to embed time codes into the video.

Another complication for analysis was that the parachutes were not marked. Marking serves two purposes in a cluster. It is a convenience for uniquely identifying each parachute, especially if the video is not continuous. Identification is needed to associate the visible state of each parachute to its riser load measurement. Also, nonsymmetric markings allow for pinpointing locations on each parachute relative to a known radial location and allows for tracking the rotation of each parachute about its axis. Any anomalies seen on the video can be compared with postflight damage assessments. Such a coded marking pattern was critical to identifying the root cause of a parachute failure during the Shuttle Solid Rocket Booster decelerator program. ${ }^{6}$ 


\section{EDU-A-TSE-1A}

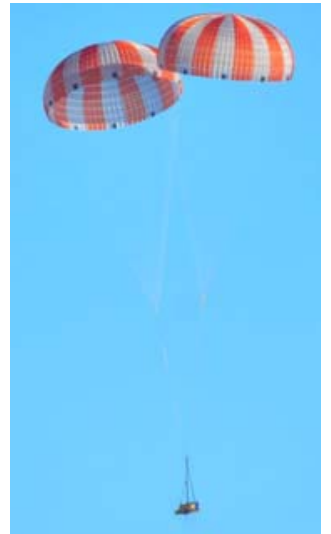

Figure 16. EDUA-TSE-1A Mains.

The first CPAS Gen II test, EDU-A-TSE-1A, was conducted on October 2, 2009. The "smart release" vehicle was a modified weight tub attached to a 9×24 ft Type V platform. The suspended weight was about 21,574 lbm to approximate the increased design Orion mass. A cluster of two Mains, seen in Fig. 16, were static line deployed by the programmer parachute and reached steady-state at about 5,200 ft MSL.

Upward-looking video was taken in HD with a Sony HDR digital camcorder and saved on the integrated MiniDV cassette tape. Black dye markings were added to the skirt in an attempt to improve skirt visibility. However, the markings near the skirt were almost always nearly perpendicular to the upward looking camera, so they were only visible during occasional skirt "roll-up.” A continuous high-contrast band was proposed to make the skirt edge more visible. However, this was decided against due to cost and possible effects on parachute material permeability. Because the Mains were not marked uniquely at this point in the test program, the parachute numbering is arbitrary.

The

fly-out angle

histories are shown in Fig. 17a. The collision events are shown as vertical bars. A histogram of the combined fly-out data is shown in Fig. 18. The maximum encountered fly-out angle was $24.80^{\circ}$ and the fitted $3 \sigma$ equivalent maximum fly-out angle is $26.32^{\circ}$.

Each of the Main parachutes included an Over-Inflation Control Line (OICL) in an attempt to control parachute breathing, and possibly prevent the excitation of cluster motion. Each OICL was $251.3 \mathrm{ft}$ in length corresponding to a diameter of $80 \mathrm{ft}$. The measured skirt perimeters are shown in Fig. 17b. In some instances, the values seem to exceed the length of the OICL, which should be the largest perimeter possible. This is probably within measurement error. A similar limitation seems

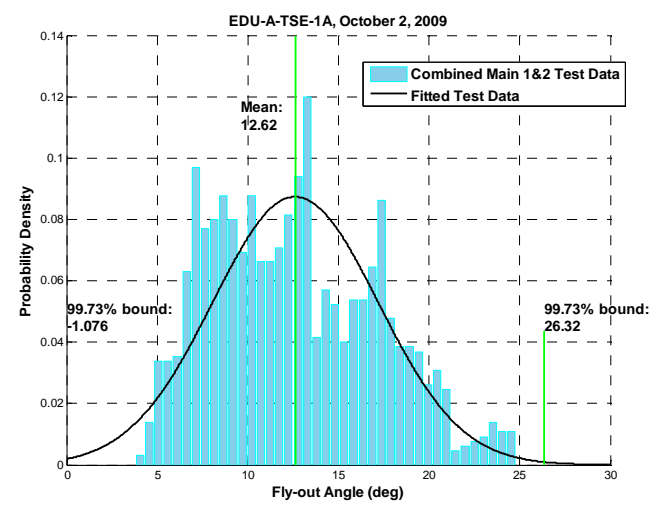

Figure 18. EDU-A-TSE-1A fly-out angle histogram.

(a)

(b)

(c)
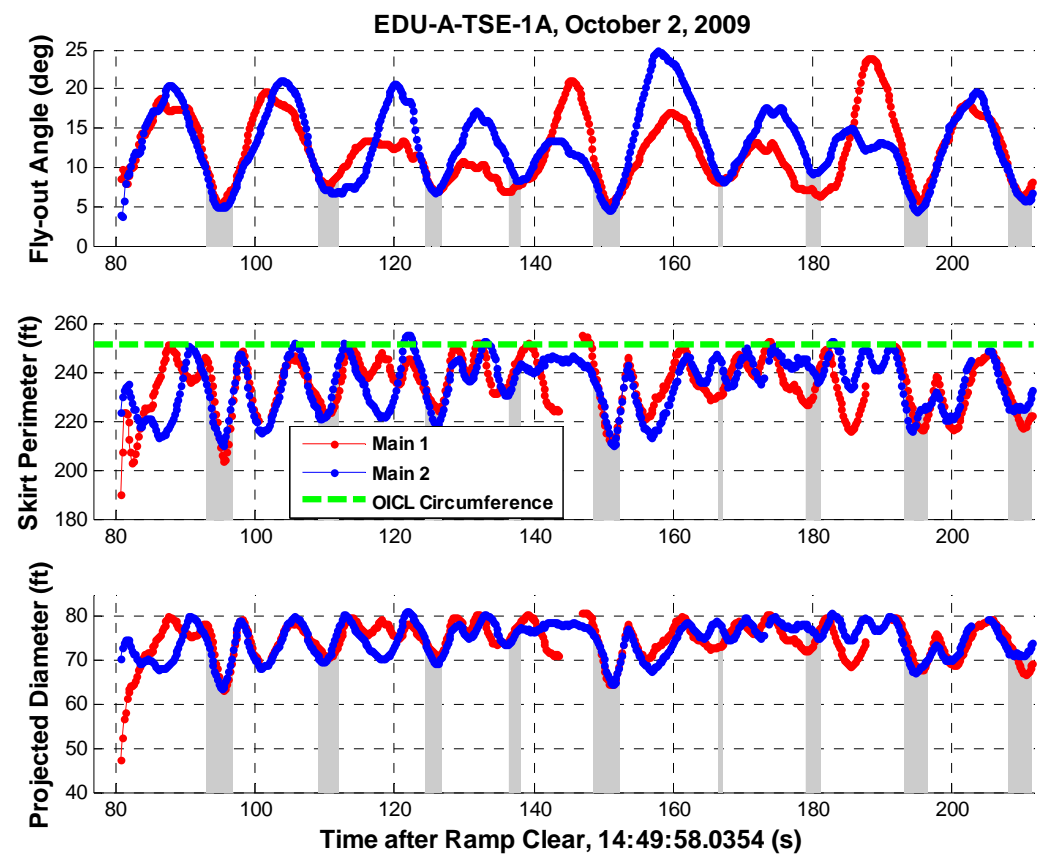

Figure 17. EDU-A-TSE-1A steady-state (a) Fly-out angles, (b) Skirt perimeters, and (c) Projected inlet diameters for each Main parachute.

visible in the equivalent projected diameter, Fig. 17c, where neither parachute exceeds $80 \mathrm{ft}$. It was not clear if the OICL was ever in tension, so a follow-on single Main test used a slightly shorter OICL. 


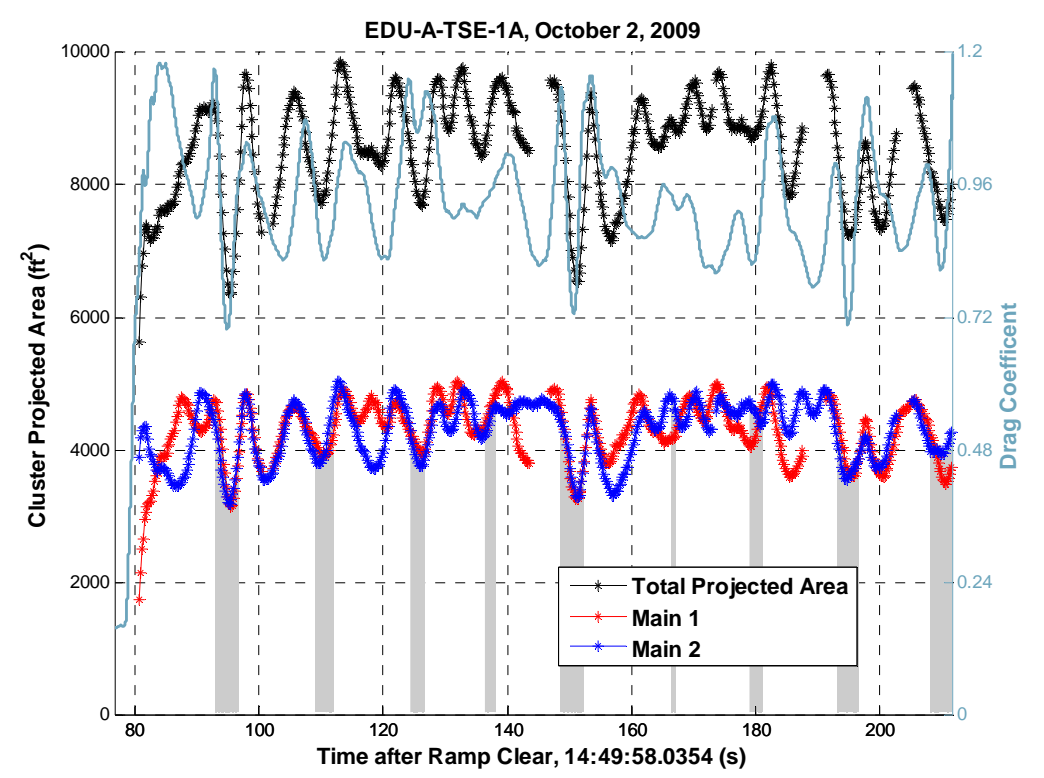

Figure 19. EDU-A-TSE-1A cluster projected area and drag coefficient.
Because the Mains were completely in the upward-looking field of view for longer than CDT-1, there is more data available to compute the total projected area. The sum and the individual components of the cluster projected area are plotted in Fig. 19. The collisions are plotted as vertical bars. The drag coefficient (plotted in light blue on the secondary axis) correlates very strongly with the total projected area. This correlation is particular strong in the "valleys" where crashing events cause a sudden loss in projected area and drag coefficient. The periodic nature of the system is most likely a combination of the long fly-out period, shorter breathing period, and compound pendulum period. 


\section{EDU-A-TSE-1B}

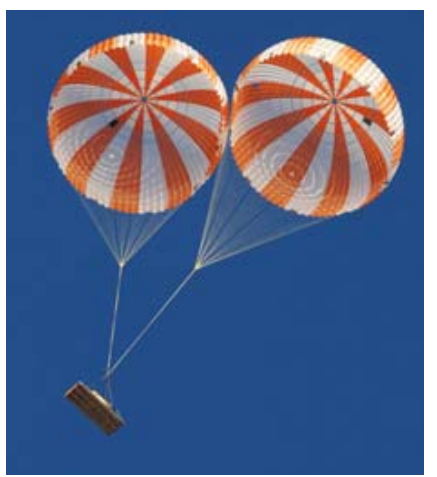

Figure 20. EDU-A-TSE1B Mains.

A history of the fly-out angles is shown in Fig. 21a. The origin for measuring fly-out angle was determined graphically from the series of multi-exposures shown in Fig. 4. A histogram of combined fly-out angles is shown in Fig. 22. The maximum experienced fly-out angle was $21.58^{\circ}$. The data were fit well to a Gaussian curve, shown in black, to calculate a mean of $12.54^{\circ}$. and a $3 \sigma$ equivalent maximum angle of $23.44^{\circ}$.

The calculated skirt perimeter for each Main is shown in Fig. 21b. Even though no OICL was present, the maximum perimeter, as well as the maximum individual OICL on the previous test was likely not short enough to restrict the canopy at this loading.

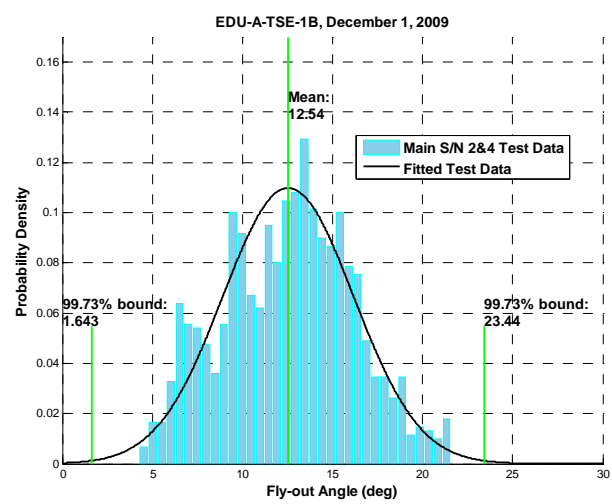

Figure 22. EDU-A-TSE-1B fly-out angle histogram. 


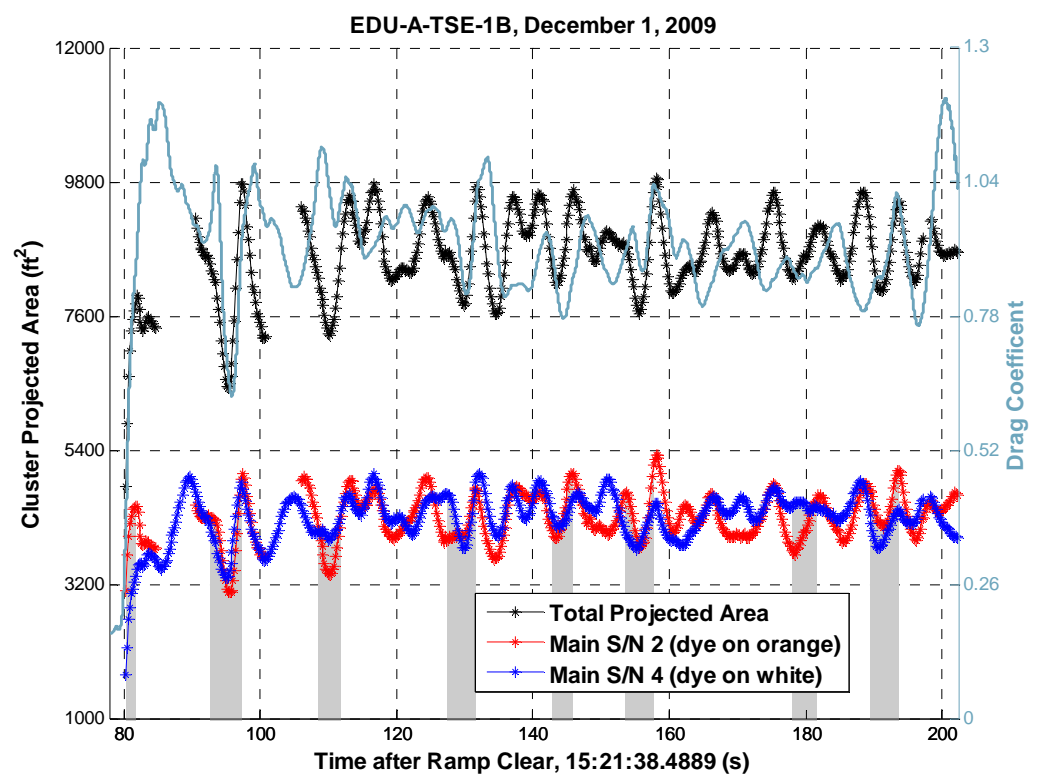

As with the previous test, the Mains were visible throughout most of the steady-state portion, allowing a computation of the total projected area, shown in Fig. 23. The drag coefficient (light blue) again has a strong correlation with the total projected area (black).

Figure 23. EDU-A-TSE-1B cluster projected area and drag coefficient. 


\section{E. Pad Abort One}

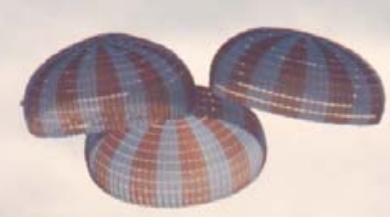

Figure 24. PA-1 Main parachutes.
The first Pad Abort demonstration test, PA-1, took place on May 6, 2010 at the White Sands Missile Range. A representative capsule shape ascended using the Launch Abort System (LAS) and descended under a sequence of CPAS parachutes. The Main parachutes are shown in Fig. 24 and Fig. 25. The steady-state descent altitude ranged from about 5,700 ft MSL to touchdown at 3,970 $\mathrm{ft}$ MSL. The suspended weight was 16,278 $\mathrm{lbm}$, which was very close to the Gen I value. Because the parachutes were not marked, parachute numbering is based on the order of final disreef to full open.

CPAS was not involved in planning the video collection for this test, but was provided digitized video files for analysis. Onboard video footage was taken with two cameras. A $16 \mathrm{~mm}$ LoCam III movie film camera

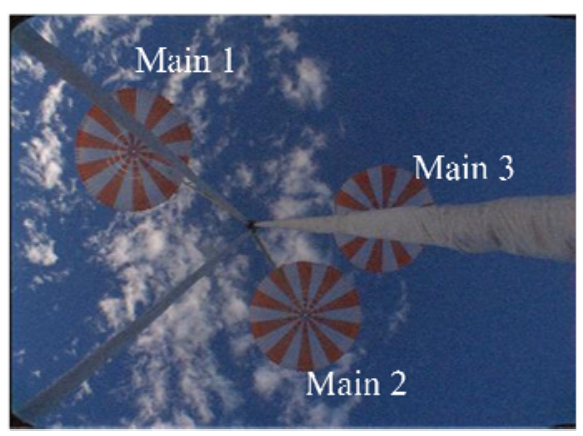

Figure 25. PA-1 onboard camera.

with a wide angle lens ran at a high speed of 200 frames per second, but only recorded for 8 seconds after the Mains fully disreefed. The other was an SD video camera which recorded through touchdown. During the overlap period, the results from both cameras matched favorably, so only the more complete data from the SD camera is presented.

The fly-out angle time histories are shown in Fig. 26a. A histogram of all the fly-out angle data is shown in Fig. 27. The mean fly-out angle was slightly higher than CDT- 1 at $16.67^{\circ}$. The maximum fly-out angle encountered was $27.46^{\circ}$ and the $3 \sigma$ equivalent value was $31.09^{\circ}$.

The cumulative results support the expected trend that fly-out angle magnitude is inversely proportional to canopy loading. Canopy loading is defined as the suspended weight divided by the total parachute surface area, $\mathrm{W}_{\text {payload }} /\left(\mathrm{N}_{\mathrm{c}} \cdot \mathrm{S}_{\mathrm{O}}\right)$. Because the "Smart Release" tests used a heavier payload and only had two Mains each, they tended to have lower fly-out angles than the more lightly loaded CDT-1 and PA-1.

Some noise is apparent in the skirt perimeter (Fig. 26b) and individual projected diameter (Fig. 26c) most likely due to the low resolution of the available video. (a)

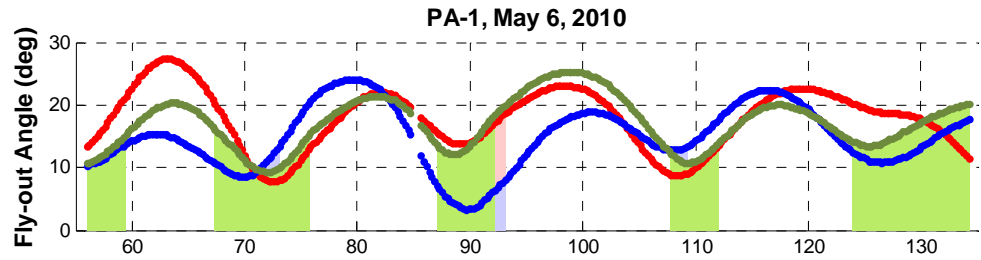

(b)

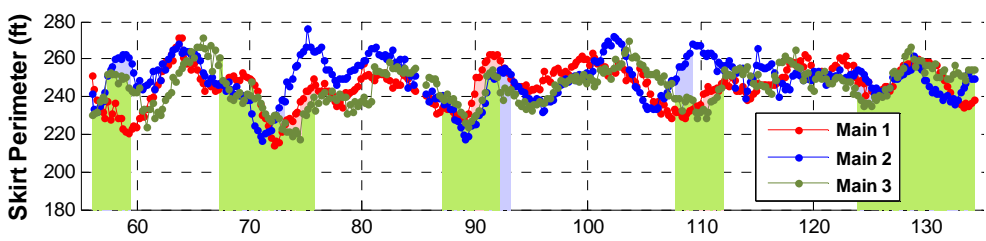

(c)

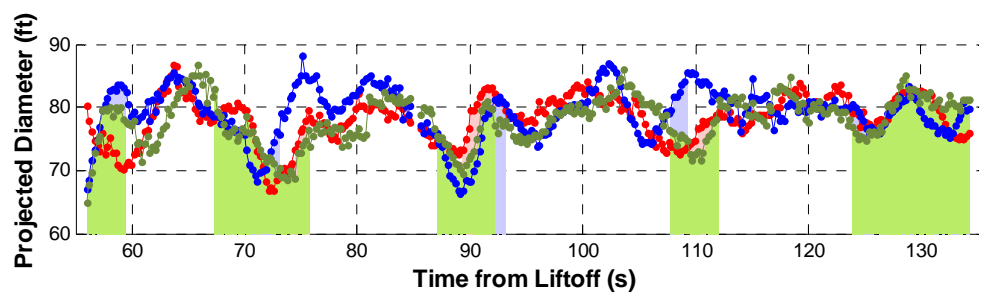

Figure 26. PA-1 steady-state (a) Fly-out angles, (b) Skirt perimeters, and (c) Projected inlet diameters for each Main parachute. 


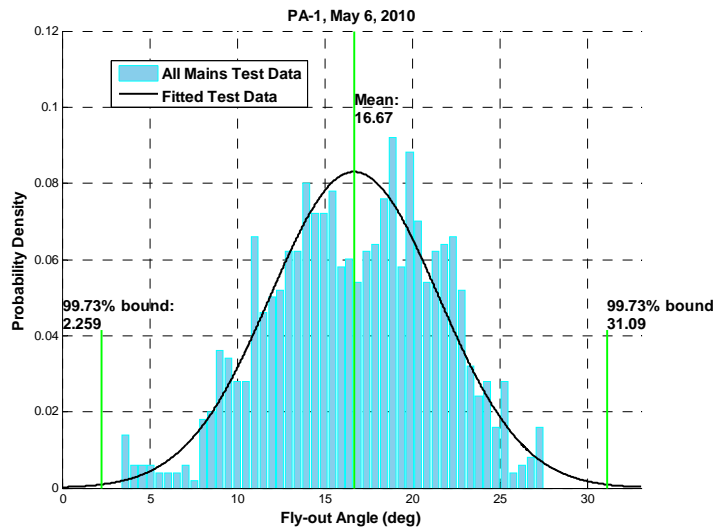

Figure 27. PA-1 fly-out angle histogram.

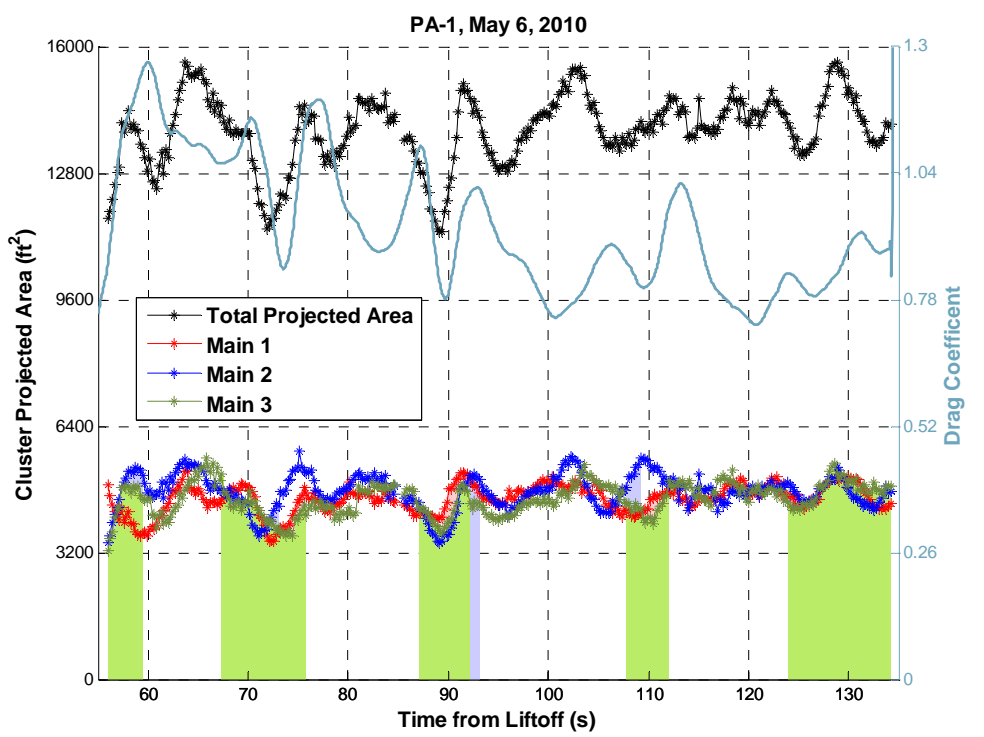

The total cluster projected area, as well as the individual parachute contributions, are plotted in Fig. 28. Only one small gap resulted from a lack of visibility. The drag coefficient (light blue) has a strong correlation to two sharp losses of total projected area (black), though both curves seem to lose correlation at lower altitudes. This divergence may be due to the high winds encountered on the day of flight. As the parachutes glide horizontally, the assumption of using purely vertical velocity for drag coefficient breaks down.

Figure 28. PA-1 cluster projected area and drag coefficient. 


\section{F. EDU-A-CDT-2-1}
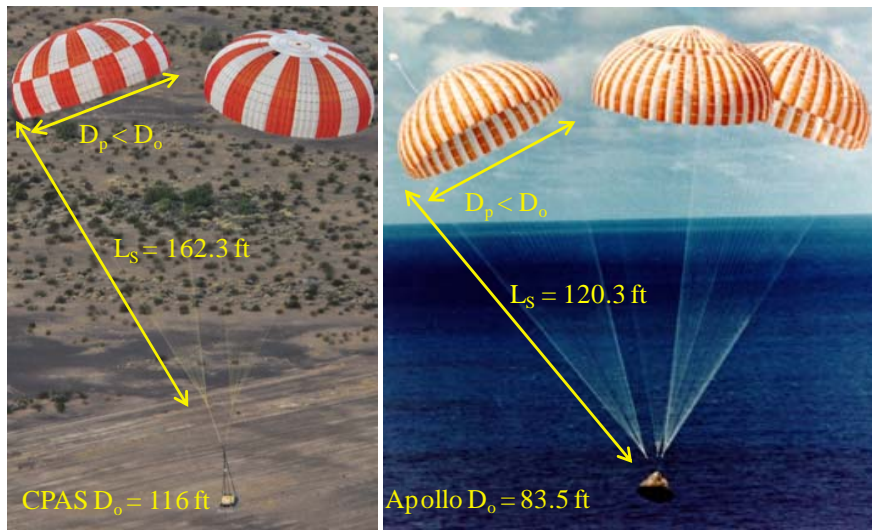

Figure 29. EDU-A-CDT-2-1 geometry (left) and Apollo geometry (right).
Test EDU-A-CDT-2-1 was conducted on July 27, 2010. The purpose was to measure the effect of modifying the Main Line Length Ratio (MLLR). The baseline CPAS ratio of suspension line, to reference diameter, $\mathrm{D}_{0}$, was about 1.15 . This test increased $\mathrm{L}_{\mathrm{s}}$ and decreased riser length, $L_{R}$, such that the $L_{s} / D_{0}$ was similar to the Apollo geometry of about 1.44, as illustrated in Fig. 29. Increasing this ratio opens up the canopy inlet, leading to higher drag performance.

Main S/N 2 (with an orange crown) unexpectedly skipped a

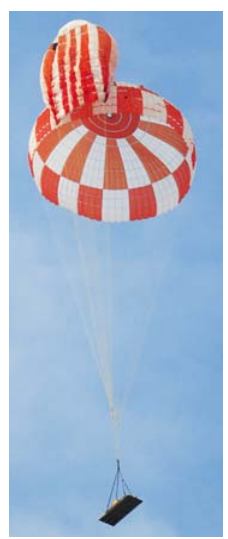

Figure 30.

Lagging Main. reefing stage and crowded out Main S/N 1 (with a white crown), as shown in Fig. 30. Both parachutes eventually inflated, steady-state descent started at about 6,380 ft MSL, and the test vehicle landed safely.

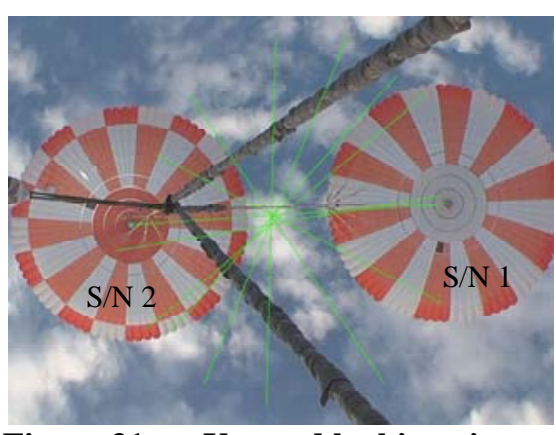

Figure 31. Upward looking view and center of rotation.

The tracking process using upward-looking cameras was complicated by clouds in the background (Fig. 31) such that the gap between sails (used as a reference geometric feature) appeared and disappeared. A series of markings near the apex was proposed to prevent this problem in the future and to facilitate automated tracking for the next ship set of Main parachutes. These parachutes did not include the markings at the skirt because they were of limited utility on previous tests.

This was the first test which successfully embedded time codes on each HD video frame. A time signal was received from a Global Positioning System (GPS) and recorded with each video file on the audio channel. After the test, the audio channel was decoded and Coordinated Universal Time (UTC) text was overlaid on each frame. This made synchronization much easier and improved the quality of test video timelines.

17

American Institute of Aeronautics and Astronautics
The different color patterns on this test made each parachute unique. The single black markings on each parachute were useful in identifying gore positions. However, it was later discovered that the orange color dyeing process leads to significantly lower material permeability than the original white. The different colors in each crown probably contributed to the uneven inflation process. Therefore, only parachutes with the same "candy stripe" color pattern at the crown will be used in future cluster tests.

(a)

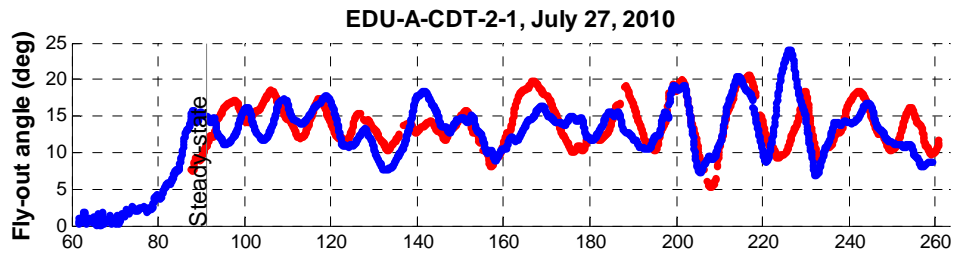

(b)

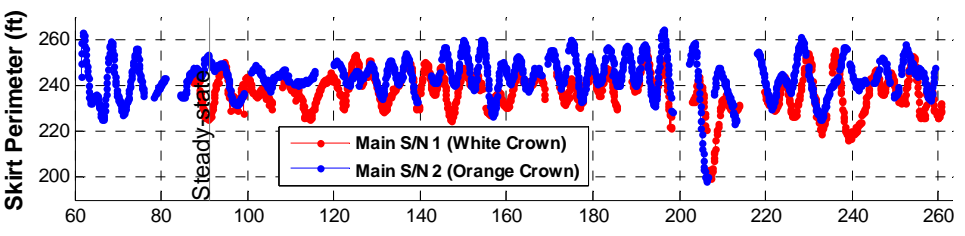

(c)

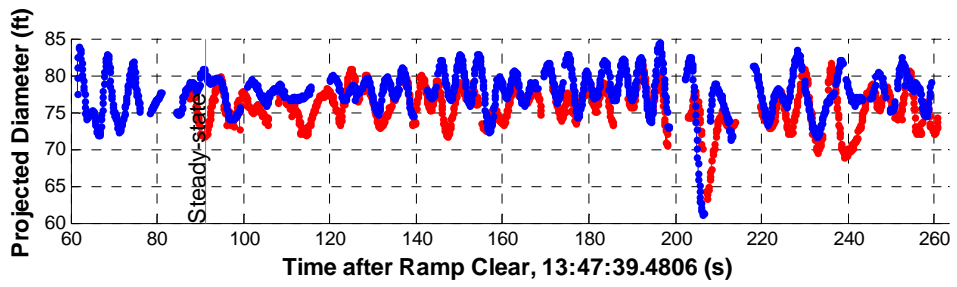

Figure 32. EDU-A-CDT-2-1 steady-state (a) Fly-out angles, (b) Skirt perimeters, and (c) Projected inlet diameters for each Main parachute. 
The fly-out angle time history plots are shown in Fig. 32a. The data from Main S/N 1 is delayed because it was "blanketed" by S/N 2. The time when the cluster decelerated to $1 \mathrm{~g}$ is marked as the beginning of steady-state descent. The mean fly-out angle was $13.87^{\circ}$ (Fig. 33). The maximum experienced fly-out angle of $24.15^{\circ}$ was slightly higher than the $3 \sigma$ maximum value of $23.06^{\circ}$.

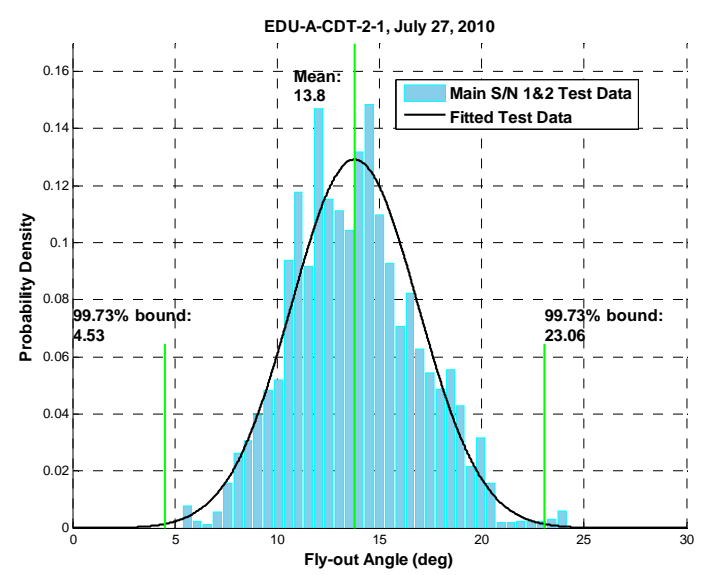

The "lead" parachute had a consistently higher perimeter (Fig. 32b) and diameter (Fig. 32c) than the lagging Main, even after both were fully open. This may be due to the porosity difference due to dyed and undyed material permeability at the crown.

Figure 33. EDU-A-CDT-2-1 fly-out histogram.

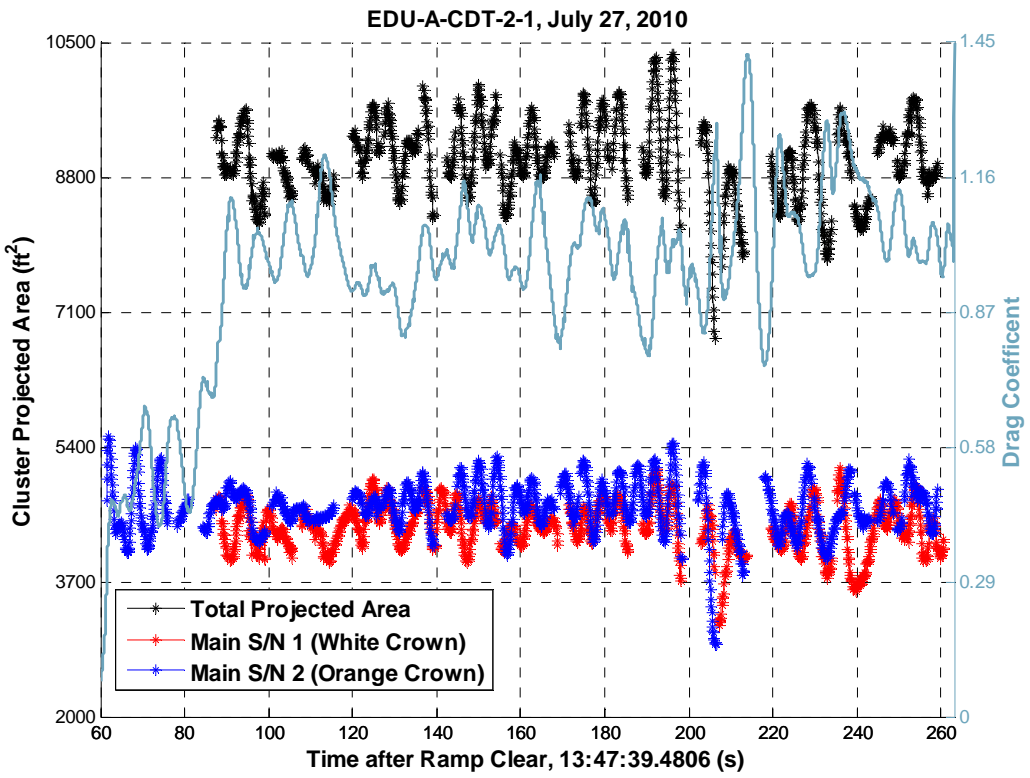

Figure 34. EDU-A-CDT-2-1 cluster projected area and drag coefficient.
In Fig. 34, the total cluster projected area (black) does not track as well with the drag coefficient (light blue) as other tests. A sudden loss in projected area occurs at about 205 seconds, and there is a large loss in drag coefficient at about 215 seconds. Unfortunately, there is a gap in the video data at the latter time. Some probable causes of discrepancies may be unsynchronized data and windinduced gliding motion.

The effective steady-state drag coefficient for this test is about 1.009 , or almost $9 \%$ higher than the baseline from tests EDU-A-TSE-1A and $1 \mathrm{~B}$, whose drag coefficients averaged to 0.927 . This exceeded the expected improvement in drag performance, so this new MLLR will be incorporated into the CPAS design. 


\section{G. EDU-A-CDT-2-2}

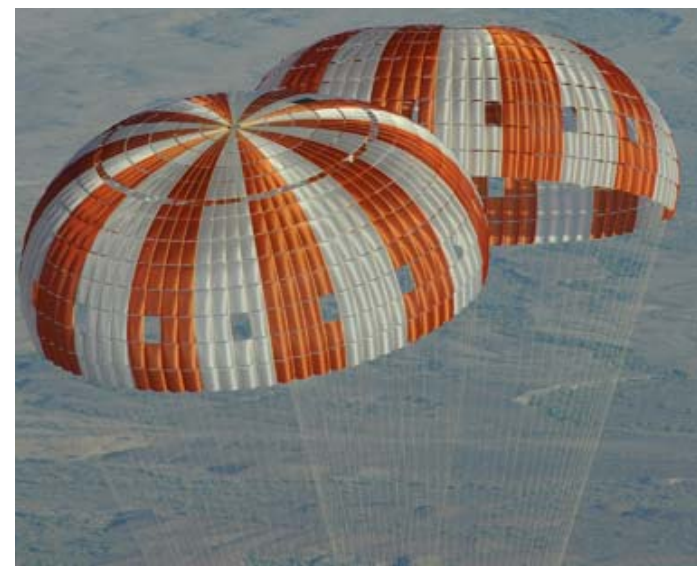

Figure 35. EDU-A-CDT-2-2 added porosity.

An intermittent problem had been encountered on previous tests using the Panasonic AG-HMR10 cameras. Although the iris, zoom, and autofocus features were turned off, the zoom motors could actuate and pull the lens out of focus during high $g$ events. This would occur randomly to about three out of every ten cameras, so the intermediate solution was to add more cameras for redundancy.

This test first replaced those models with more expensive Hitachi HV-HD30 cameras with no moving parts to pull out of focus. The iris and focus on each camera are manually set before installation by testing the image on a target at the expected camera-to-parachute distance. The cameras have performed flawlessly to date.

Video tracking of the vents shows that the fly-out angles oscillate after the inflation to full open, but soon damp significantly as predicted. The fly-out angle histories are shown in Fig. 36, as well as histograms of each regime. The narrower spectrum in the damped region indicates improved cluster stability.

More thorough tracking of each skirt is underway, so analyses based on the parachute shapes are pending. However, the cluster stability regimes are noticeable in the drag coefficient based on the vertical velocity, in Fig. 37. The sudden rise in drag coefficient after 260 seconds is likely an artifact of an inversion layer near the ground.

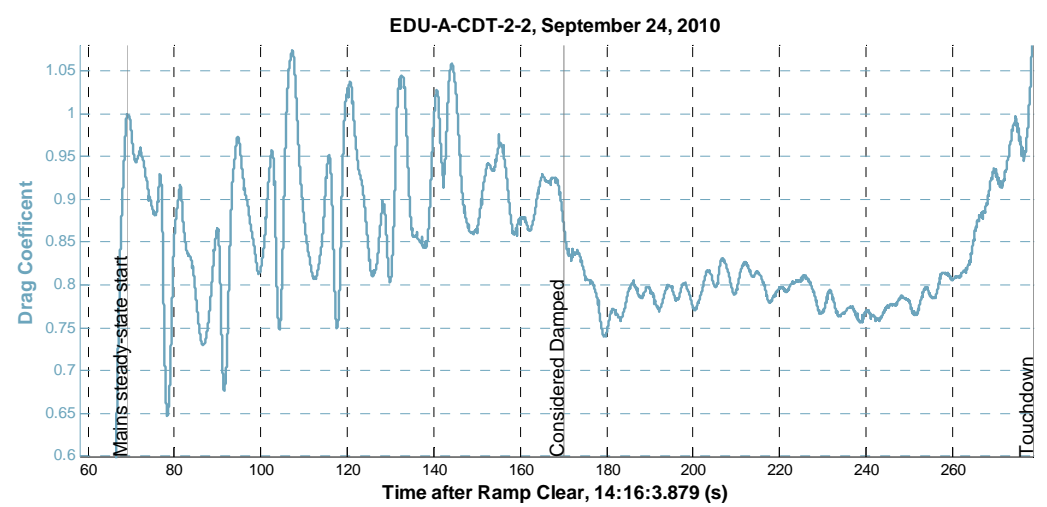

Figure 37. EDU-A-CDT-2-2 drag coefficient.
Test EDU-A-CDT-2-2 varied the geometric porosity of the Main parachutes by adding a ring gap and removing several side panels, as shown in Fig. 35. The goal was to reduce cluster oscillations. The MLLR for this test was the value baseline prior to EDU-A-CDT-2-1 of 1.15. The test was conducted successfully on September 24, 2010. Main steady-state descent started at about 8,170 ft MSL.

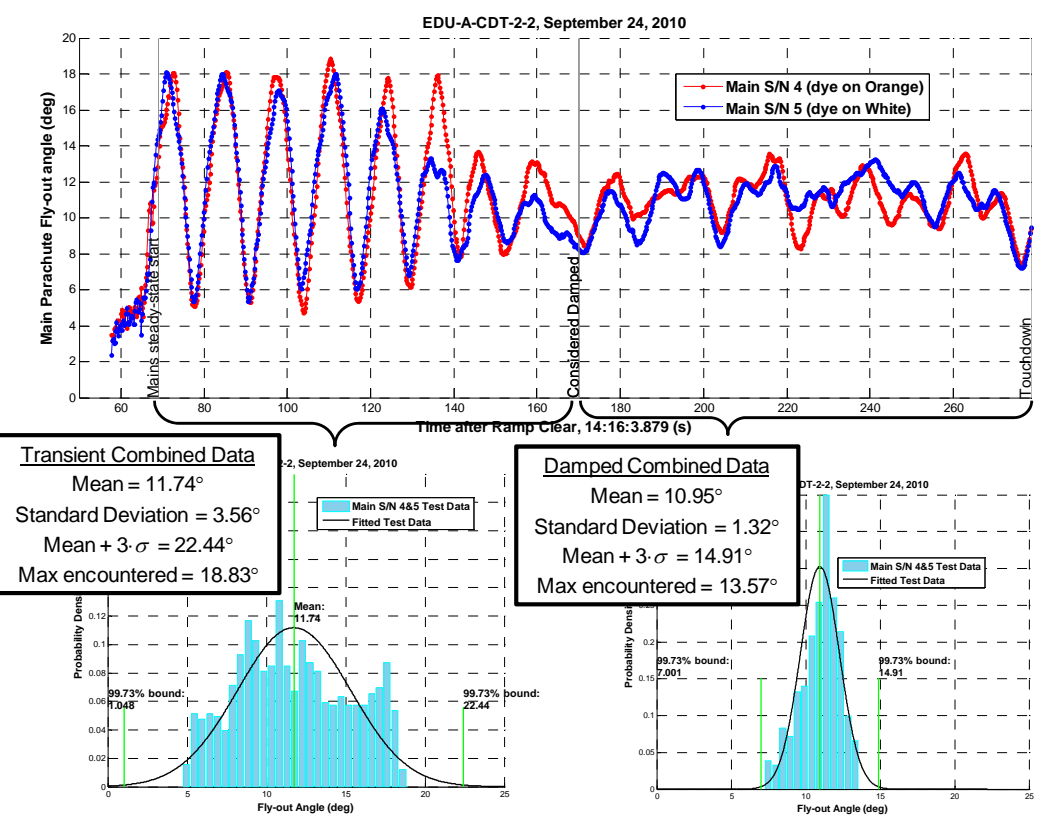

Figure 36. EDU-A-CDT-2-2 fly-out angles and histograms. 
H. EDU-A-CDT-2-3

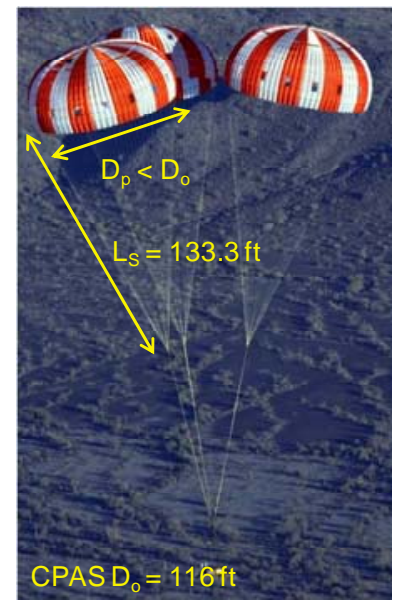

Figure 38. EDU-A-

CDT-2-3 added porosity.

Individual skirt tracking analysis is still pending, but some of the features of the fly-out angles can be seen in the drag coefficient plot of Fig. 40. The loss in drag is apparent during the first cluster "crash" at about 80 seconds. The equilateral formation is the most efficient for a three parachute cluster, as shown by the favorable drag generated at about 200 seconds.
The next cluster test increased the number of Main parachutes from two to three using the new geometric porosity. However, at this point, the new MLLR still had not been incorporated into the design, so the suspension line lengths were the same as the Gen I baseline, as shown in Fig. 38. EDU-A-CDT-2-3 was conducted successfully on December 7, 2010. The Mains achieved steady-state at about 5,840 ft MSL.

Because of the added degree of freedom from the third parachute, the fly-out angles did not remain synchronized for as many cycles as in the two-cluster test. Only about three even oscillations in fly-out angle can be seen in Fig. 39. The damping was not as obvious as in EDU-A-CDT-2-2, but the narrower spectrum in fly-out angles appears to be present in the histogram analysis.

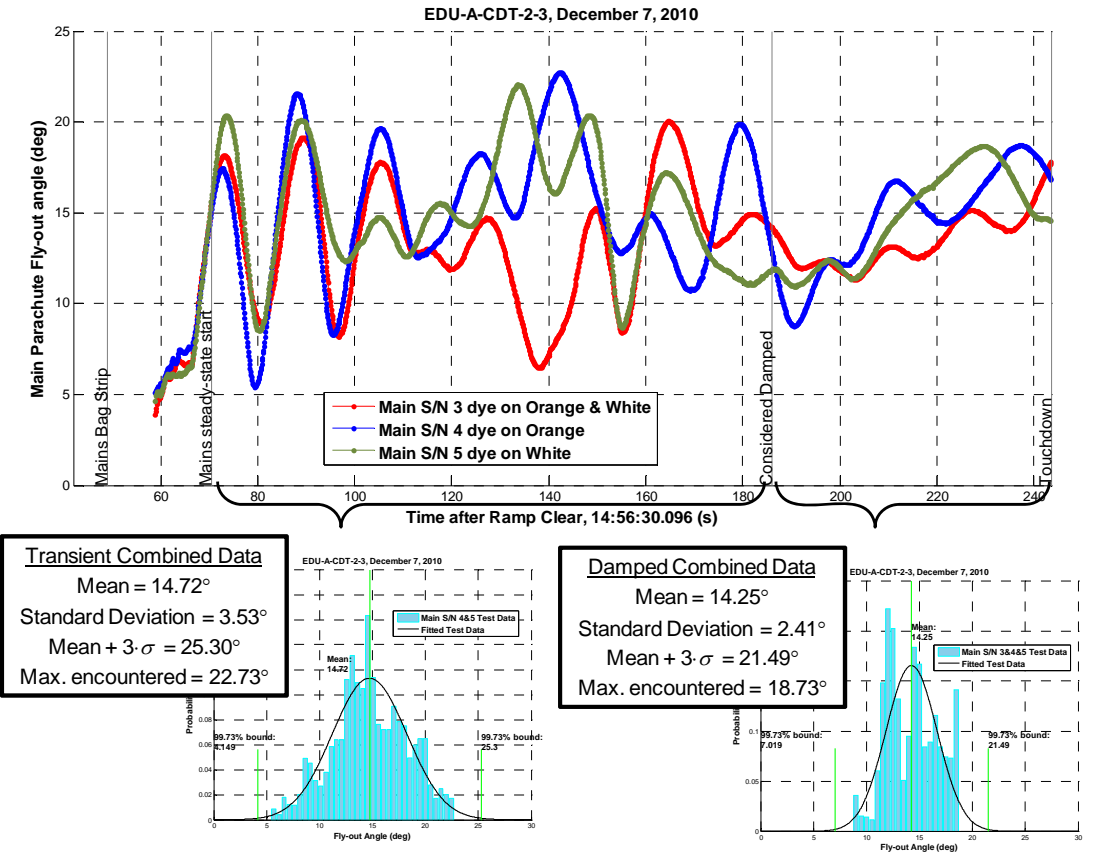

Figure 39. EDU-A-CDT-2-3 Fly-out angles and histograms.

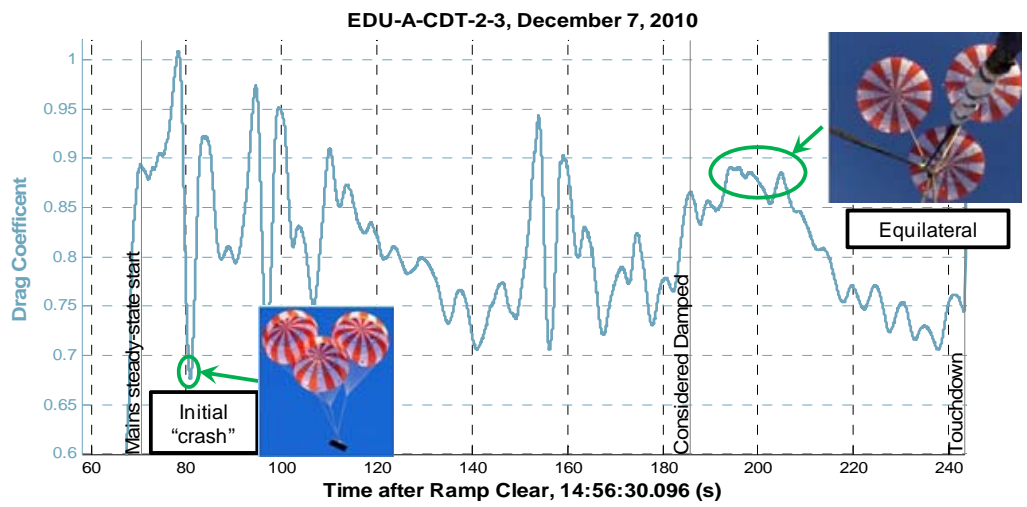

Figure 40. EDU-A-CDT-2-3 drag coefficient. 


\section{Conclusion}

The performance of a cluster of parachutes during steady-state descent is generally determined by measurements of the payload vertical velocity. The amount of drag generated is dependent on the amount of area presented by the canopies. It was shown that the measurements of the shape of parachute inlets combined with the formation of each parachute in the cluster could be correlated with the drag coefficient. The magnitudes of fly-out angles are indirectly proportional to the system canopy loading. That is, fewer parachutes and a heavier payload tend to reduce fly-out angles. The loss of area during parachute collisions is the largest contributor to loss of cluster drag. Design changes to improve parachute cluster stability can therefore reduce magnitude and/or variation of the rate of descent of the CM. Work is currently being performed to characterize the periodic nature of cluster geometry in order to realistically simulate terminal performance of the Orion vehicle.

There were several lessons learned for video analysis from flight tests. The quality of results is dependent on choosing cameras and lenses with high resolution and adequate field of view. Planning with 3-D pre-visualization software has proven valuable. The cameras must be securely mounted to improve accuracy, but must be adequately protected from shocks and vibration. Solid state video recorders are much more reliable than cassette tapes for continuously recording through dynamic events. Overlaying time codes on video is useful for synchronization with other data sources. Marking canopies uniquely and asymmetrically can speed up analysis by associating the visual behavior of each canopy with its riser tension data. Future tests will add more markings to automate feature tracking which is currently labor intensive. However, significant amounts of different colors can cause varying material permeability and alter performance between parachutes.

\section{Acknowledgments}

The authors wish to thank the Team for Advanced Flow Simulation and Modeling (T*AFSM) for providing estimates of parachute geometry and predicting the effects of varying lengths of an OICL and alternate geometric porosities. T*AFSM is located at the Department of Mechanical Engineering and Materials Science of Rice University in Houston, Texas, and is led by Professor Tayfun Tezduyar. Video configuration management, installation, and pre-visualization were conducted by the CPAS video team of Robert Rimes and Marcos Jaramillo. Much of the image tracking was performed by co-operative student Sean Duvall. Kevin Crosby of Jacobs Engineering assisted with the fly-out angle and diameter analysis. Co-operative student Chris Russo helped to synchronize video with cluster data and identify parachutes.

\section{References}

\footnotetext{
${ }^{1}$ Strickert, Gordon and Jann, Thomas, "Determination of the Relative Motion Between Parafoil Canopy and Load Using Advanced Video-Image Processing Techniques,” 1999, AIAA paper 99-1754.

${ }^{2}$ Yakimenko, Oleg, Berlind, Robert and Albright, Chad, "Status on Video Data Reduction and Air Delivery Payload Pose Estimation,” 19th AIAA Aerodynamic Decelerator Systems Technology Conference and Seminar, Williamsburg, VA, May 21 24, 2007, AIAA paper 2007-2552.

${ }^{3}$ Photo-Sonics, Inc., “TrackEye Motion Analysis Software," [online], URL: http://www.photosonics.com/trackeye_software.htm [cited: February 13, 2011].

${ }^{4}$ Ray, Eric S. "Measurement of CPAS Main Parachute Rate of Descent," May 23 - 26, 2010. 21st AIAA Aerodynamic Decelerator Systems Technology Conference and Seminar, Dublin, Ireland. (submitted for publication).

${ }^{5}$ Team for Advanced Flow Simulation and Modeling, “Orion Spacecraft Parachutes,” [online], URL: http://www.tafsm.org/PROJ/AS/Orion08A [cited: February 14, 2011].
} 